\title{
Análise do Gerenciamento dos Resíduos Sólidos no município de Belém de Maria - Pernambuco
}

\author{
Jaisy GONÇALVES \\ Universidade Federal de Pernambuco (UFPE/CAA), Caruaru, PE, Brasil \\ Luciana CRAMER \\ Universidade Federal de Pernambuco (UFPE/CAA), Caruaru, PE, Brasil \\ Ítalo Cavalcante da Silva SOARES \\ Universidade Federal de Pernambuco (UFPE/PROPAD), Recife, PE, Brasil
}

\author{
Received 24 Out. 19; Accepted 10 Nov. 19 \\ Evaluation System: Double Blind Review \\ Editor: Jose Lindenberg Julião Xavier Filho, Dr. \\ ISSN: 2594-8040
}

To cite this paper: Gonçalves, J., Cramer, L., \& Soares, I. C. S. (2019). Análise do gerenciamento dos resíduos sólidos no município de Belém de Maria - Pernambuco. Journal of Perspectives in Management - JPM, 3(2), p. 21-34.

\section{Resumo}

Este artigo tem o objetivo de analisar o gerenciamento dos resíduos sólidos no município de Belém de Maria - Pernambuco. A pesquisa foi realizada através de estudo de caso, pesquisa bibliográfica e de campo. Foram realizados entrevistas e questionários, à gestão pública e à população, vislumbrando obter dados do posicionamento deles frente o gerenciamento e à problemática dos resíduos sólidos na cidade. Os resultados obtidos apontam que existem serviços de coleta, porém, as maneiras corretas de disposição dos resíduos sólidos não estão sendo cumpridas, visto que os resíduos são recolhidos e despejados em pontos afastados do cenário urbano para depois seguir para a destinação final: o lixão. Ressalta-se, porém, que a população é conhecedora do cenário existente, do mesmo modo que identifica os problemas causados pelo lixo, no entanto, apresentam posturas condenáveis de educação ambiental. Assim, esta pesquisa permitiu também compreender a necessidade de mudanças na gestão de resíduos sólidos, tais como: implantação de coleta seletiva, participação na formação de consórcios públicos, tratamento de resíduos sólidos através da reciclagem e compostagem, e ações de educação ambiental que contribuam para despertar a necessidade de colaboração política e da população.

Palavras-Chave: Resíduos sólidos urbanos, Lixo, Percepção ambiental, Gestão, Belém de Maria Pernambuco. 


\section{Introdução}

A crise ambiental, em função da ação antrópica, é crescente e causa desastres e desequilíbrios que modificavam e modificam o espaço natural. Como consequência, a degradação do meio ambiente tornou-se algo constante, o que fez com que a sociedade, governos e estudiosos sobre a temática pensassem em estratégias para minimizar os impactos causados ao meio ambiente.

Passos (2009) relata que a Conferência das Nações Unidas para o Meio Ambiente Humano, realizada em 1972 em Estocolmo - Suécia, foi a primeira Conferência global voltada para este assunto, e é considerada um marco histórico político internacional decisivo para o surgimento de políticas de gerenciamento ambiental. Depois da Conferência de Estocolmo, outros eventos foram realizados, como a Rio-92; a Rio+10, em 2002, e a Rio+20, em 2012, todos com o objetivo de promover a preservação do meio ambiente e de garantir o desenvolvimento sustentável.

$\mathrm{O}$ enfrentamento à crise ambiental aponta as necessidades de tomada de consciência ambiental, quebra de paradigmas e mudança de atitudes da sociedade, em que essas mudanças dizem respeito, sobretudo, ao crescimento econômico e populacional, às formas de produção e de exploração da natureza e aos hábitos de consumo da sociedade (Bigliardi \& Cruz, 2005). Assim, este artigo volta-se ao estudo de um problema ambiental em particular: os resíduos sólidos.

À medida que a população cresce, aumenta-se também a quantidade de resíduos despejados nos centros urbanos, muitas vezes sem gerenciamento adequado por partes dos poderes governamentais, mesmo mediante as leis. No entanto, a gestão e a disposição inadequada dos resíduos causam impactos socioambientais, tais como degradação do solo, comprometimento dos corpos d'água e mananciais, intensificação de enchentes, contribuição para a poluição do ar e proliferação de vetores de importância sanitária nos centros urbanos (Besen et al., 2010).

No Brasil, a gestão dos resíduos sólidos urbanos atualmente é direcionada pela Lei nº 11.445 , que estabelece Diretrizes Nacionais para o Saneamento Básico (Lei Nacional de Saneamento Básico - LNSB) (Brasil, 2007), e pela Lei n 12.305, que elabora a Política Nacional de Resíduos Sólidos (PNRS) (Brasil, 2010). Diante dessas leis, os estados e municípios ficam obrigados a cumprir as exigências e determinações impostas pela lei. Contudo, a correta gestão dos resíduos sólidos é um problema enfrentado por grande parcela dos municípios brasileiros.

Medeiros (2012) diz que existem alguns obstáculos, principalmente nos municípios de pequeno porte em relação a destinação adequada dos seus resíduos sólidos. Na Região Nordeste a situação ainda é muito mais agravante, visto que de acordo com o Instituto Brasileiro de Geografia e Estatística - IBGE, (2010), 89,3\% dos municípios têm os lixões como forma de destinação final.

Assim sendo, este estudo será realizado no Munícipio de Belém de Maria, localizado na Mata Sul de Pernambuco, cuja população é de 11.353 habitantes, de acordo com o censo de 2010 realizado pelo Instituto Brasileiro de Geografia e estatística - IBGE.

Considerando a problemática em torno do gerenciamento dos resíduos sólidos, este estudo se propõe a responder a seguinte pergunta de pesquisa: o gerenciamento dos resíduos sólidos urbanos no município de Belém de Maria, Pernambuco, é realizado de forma adequada?

Para responder à pergunta de pesquisa, este artigo tem como objetivo analisar o gerenciamento dos resíduos sólidos urbanos no município de Belém de Maria - Pernambuco. São objetivos específicos do estudo: I. conhecer o cenário dos resíduos sólidos urbanos no município de Belém de Maria, PE; II. diagnosticar o gerenciamento dos resíduos sólidos urbanos no município de Belém de Maria; III. identificar a percepção da população sobre a gestão dos resíduos sólidos urbanos e IV. Propor soluções capazes de potencializar a efetividade da gestão dos resíduos sólidos urbanos no município. 


\section{Referencial Teórico}

\subsection{Problemática ambiental e a busca pela sustentabilidade}

A primeira percepção da humanidade sobre a questão ambiental e a existência de um risco ambiental em escala global, deu-se na década de 1950, com o experimento de armas nucleares, o que causou poluição nuclear, mesmo em locais distantes (Nascimento, 2012 apud Santos et al., 2018). No final da década de 1960, ocorreram ainda inúmeros acidentes ambientais como o derramamento de petróleo na costa oeste da Inglaterra e no Alasca, poluindo mares e oceano, contaminando praias e matando inúmeros animais (Bernardes \& Ferreira, 2007; Nascimento, 2012, apud, Santos et al., 2018).

Assim, em virtude de tais acontecimentos Gurski, Gonzaga e Tendolini (2012), relatam que surgiram debates em torno dos desafios enfrentados pelo meio ambiente na mídia e no meio acadêmico. Em 1968, a Organização nas Nações Unidas para Educação, a Ciência e a Cultura UNESCO, organizou a conferência sobre a Biosfera em Paris, simbolizando a consciência da perda de qualidade do meio ambiente, colocando esse termo meio ambiente no lugar do então usada "natureza". Também foi nesse período que um grupo de pessoas reconhecidas, de diferentes áreas, conhecido como Clube de Roma, empenhou seus estudos na política e economia global, utilizando de fórmulas matemáticas para tratar do meio ambiente e discutir sobre o desenvolvimento sustentável (Gurski, Gonzaga \& Tendolini, 2012).

Ainda segundo Gurski, Gonzaga e Tendolini (2012), apenas no ano de 1972 a Organização das Nações Unidas - ONU realizou a primeira Conferência Mundial sobre o homem e o Meio Ambiente, conhecida também como Conferencia de Estocolmo, na qual foi criada a Declaração de Estocolmo, cujo objetivo era descrever as responsabilidades e nortear as políticas futuras relativas ao meio ambiente apoiadas no Plano de Ação para o meio ambiente composta por 109 recomendações (Gurski, Gonzaga \& Tendolini, 2012). Assim, diante dos fatos, Bellen (2005) afirma que o conceito de desenvolvimento sustentável surgiu dentro do cenário em que os padrões de vida eram incompatíveis com o processo de regeneração do meio ambiente, ou melhor, que o termo desenvolvimento ligado a ideia de crescimento, foi o limite para que surgisse o termo de desenvolvimento sustentável.

Costanza (1991) reitera que o desenvolvimento sustentável deve ser inserido na relação dinâmica entre o sistema econômico e o ecológico, e que para ser sustentável, essa relação deve assegurar que a vida humana possa continuar indefinidamente, com crescimento e desenvolvimento da sua cultura. Nessa perspectiva, o homem, no sentido mais abrangente, tem papel fundamental no percurso rumo à sustentabilidade. Amorim (2010) destaca que o modo de vida, a cultura, o trabalho, a alimentação, a higiene e o consumo dos humanos interferem diretamente na produção de resíduos sólidos. Assim, a gestão dos resíduos torna-se indispensável para o alcance da sustentabilidade.

\subsection{Resíduos sólidos versus lixo}

Segundo a norma brasileira NBR 10004, de 2004, resíduos sólidos são os resíduos nos estados sólido e semissólido, que resultam de atividades de origem industrial, doméstica, hospitalar, comercial, agrícola, de serviços e de varrição. Ficam incluídos nesta definição os lodos provenientes de sistemas de tratamento de água, aqueles gerados em equipamentos e instalações de controle de poluição, bem como determinados líquidos cujas particularidades tornem inviável o seu lançamento na rede pública de esgotos ou corpos de água, ou exijam para isso soluções técnica e economicamente inviáveis em face à melhor tecnologia disponível.

Já Lixo é uma palavra latina (lix) que significa cinza, vinculada às cinzas dos fogões. Segundo Ferreira (1999), lixo é "aquilo que se varre da casa, do jardim, da rua e se joga fora; entulho. Tudo o que não presta e se joga fora. Sujidade, sujeira, imundície. Coisa ou coisas inúteis, 
velhas, sem valor". Jardim e Wells $(1995$, p. 23$)$ definem lixo como "[...] os restos das atividades humanas, considerados pelos geradores como inúteis, indesejáveis ou descartáveis" (Ferreira, 1999, apud Mucelin e Bellini, 2008, p. 113).

D'Almeida e Vilhena (2000) dividem o lixo em duas categorias: lixo molhado e lixo seco. Os primeiros considerados como lixo úmido, são os restos orgânicos de origem vegetal e animal que decorrem do preparo de alimentos, do desperdício e da poda de jardins e logradouros públicos. Os outros são as embalagens pós-consumo, sucatas e objetos em desuso que se constituem de papel, papelão, plástico, metal, vidro, couro etc. Entre os componentes do lixo seco se encontram itens de origem orgânica, como, por exemplo, os resíduos celulósicos, restos de fibras vegetais, tecidos de origem animal e os constituídos de resinas termoplásticas derivadas do petróleo. Entre esses componentes também foram considerados os rejeitos, ou seja, materiais que não têm condições técnicas de reciclagem ou não despertam interesse comercial da cadeia produtiva desse segmento (comerciante, industrial, etc.) (D’Almeida \& Vilhena, 2000 apud Vieira, 2006).

De acordo com sua origem, Jardim (1996) citado por Junior (2004) classifica-os como industrial; urbanos; serviços de saúde; portos, aeroportos, terminais rodoviários e ferroviários; Construção e demolição; agrícolas e radioativos.

\subsection{Geração e Tratamento dos resíduos sólidos}

Para Jacobi e Besen (2011) a administração pública municipal tem responsabilidade de gerenciar os resíduos sólidos urbanos, seja ele domiciliar, público ou comercial, de forma que seja realizado de maneira ambientalmente segura, desde sua geração/coleta até a disposição final, porém este fato continua sendo um dos grandes desafios até os dias atuais, já que geralmente os resíduos não passam por um processo de destinação que seria uma forma de tratamento abordando a reutilização, recuperação ou reciclagem; seguindo diretamente para a disposição em aterros ou lixões.

Dias (2000) diz que a geração de resíduos é proporcional ao aumento da população e desproporcional à disponibilidade de soluções para o gerenciamento dos detritos, resultando em sérias defasagens na prestação de serviços, tais como a diminuição gradativa da qualidade do atendimento, a redução do percentual da malha urbana atendida pelo serviço de coleta e o seu abandono em locais inadequados. Equacionar o desequilíbrio entre o incremento de resíduos e as escassas possibilidades de dispô-lo corretamente sem agredir a saúde humana e sem causar riscos ao meio ambiente é o grande desafio que se impõe segundo o mesmo autor (Dias, 2000, apud Silva et al., 2016).

Assim, o tratamento dos resíduos sólidos tem um papel fundamental na sociedade, pois visa diminuir os impactos negativos a saúde humana, assim como no meio ambiente, consistindo em um conjunto de operações e métodos necessários para a utilização correta das legislações aplicáveis aos resíduos sólidos, que vai desde sua produção até seu destino final. No entanto, por não disporem de recursos suficientes e terem pouca capacidade técnicas na gestão dos serviços de limpeza pública, coleta seletiva e tratamento de resíduos, os munícipios de pequeno e médio porte no Brasil, têm dificuldade para tratar os resíduos sólidos. Então, como solução para este problema, a formação de consócios públicos municipais ou interfederativos pode proporcionar a sustentabilidade dos serviços prestados e a divisão das despesas, além de contribuir para a inclusão social de catadores e a desativação de lixões (Brasil, 2011, p. 6 apud Medeiros, 2012).

No Brasil, a coleta porta-a-porta tem sido o sistema mais utilizado tanto na coleta do lixo domiciliar como na coleta seletiva. Os garis correm em média oito horas por dia atrás dos caminhões, carregando sacos de lixo, que podem chegar a pesar até $20 \mathrm{~kg}$. Da quantidade de resíduos coletados em nosso país, apenas $1,7 \%$ recebe algum tipo de tratamento antes de ser conduzido para a destinação final (Ribeiro e Lima, 2000, apud, Leme, 2009). Como formas de 
tratamento, a coleta seletiva se caracteriza pelo reaproveitamento de resíduos que normalmente chamamos de lixo e deve sempre fazer parte de um sistema de gerenciamento integrado de lixo.

Nas cidades, a coleta seletiva é um instrumento concreto de incentivo a redução, a reutilização e a separação do material para a reciclagem, buscando uma mudança de comportamento, principalmente em relação aos desperdícios inerentes à sociedade de consumo. Dessa forma, compreende-se que é preciso minimizar a produção de rejeitos e maximizar a reutilização, além de diminuir os impactos ambientais negativos decorrentes da geração de resíduos sólidos (Ribeiro; Lima, 2000). De acordo com Waite (1995), entre as vantagens ambientais da coleta seletiva destacam-se: a redução do uso de matéria-prima virgem e a economia dos recursos naturais renováveis e não renováveis; a economia de energia no reprocessamento de materiais se comparada com a extração e produção a partir de matérias- primas virgens e da valorização das matérias-primas secundárias, e a redução da disposição de lixo nos aterros sanitários e dos impactos ambientais decorrentes. Os materiais recicláveis tornaram-se um bem disponível e o recurso não natural em mais rápido crescimento (Waite, 1995 apud Ribeiro \& Besen, 2006).

Para Jardim (1995) reciclagem é o resultado de uma série de atividades por vias de materiais que se tornariam lixo ou estão no lixo e são desviados, sendo coletados, separados e processados para serem usados como matéria-prima na manufatura de bens feitos anteriormente apenas com matéria-prima virgem. Traz benefícios como a diminuição da quantidade de lixo a ser aterrada (consequentemente aumenta a vida útil dos aterros sanitários), preservação de recursos naturais, economia de energia na produção de novos produtos, diminuição dos impactos ambientais, novos negócios e geração de empregos diretos e indiretos através da criação de indústrias recicladoras.

A reciclagem não pode ser vista como a principal solução para o lixo, é uma atividade econômica que deve ser encarada como um elemento dentro de um conjunto de soluções (Jardim, 1995 apud Junkes, 2012). Para calcular os benefícios econômicos gerados pela reciclagem pode tomar como base a diferença entre os custos gerados pela produção a partir de matéria-prima virgem e os custos gerados para a produção dos mesmos bens a partir de material reciclável.

Também pode-se citar como formas de tratamento dos resíduos sólidos a incineração e compostagem. A incineração trata-se de uma queima do resíduo, transformando-o em cinzas. Tem sua utilização limitada, pois gera resíduos indesejáveis que devem ser controlados, além do elevado custo de operacionalização. Pode-se justificar seu uso no caso de lixo hospitalar ou resíduo contaminado (Garcia \& Rodrigues, 2007). E a compostagem é um processo biológico de decomposição da matéria orgânica contida em restos de origem animal ou vegetal tendo como resultado final um produto que é o composto orgânico; que pode ser aplicado ao solo para melhorar suas características sem ocasionar risco ao meio ambiente (D’Almeida, 2000 apud Junkes, 2012).

\subsection{Disposição final dos resíduos sólidos}

A disposição final adequada dos resíduos sólidos ainda continua sendo um dos maiores problemas enfrentados pela administração pública, pois boa parte dos municípios do país despeja seus resíduos em lixões a céu aberto com ausência de tratamento. Pacheco (2004) define que os vazadouros a céu aberto, ou lixão, se caracterizam por serem depósitos a céu aberto onde o lixo é apenas dispensado, sem nenhum tratamento dos resíduos da decomposição. Por isso, há alta contaminação do solo e da região ao redor desses lixões, e contaminação do lençol freático pela percolação do chorume no solo.

A justificativa para tal fato muitas vezes se dá devido à falta de recurso para implementação de ações corretas, bem como a escassez de áreas disponíveis para instalação de aterros sanitários. Assim, deve se incentivar a seletividade e reciclagem, através da colaboração de cada cidadão com o intuito de diminuir a quantidade de resíduos lançados nos aterros, para aumentar o tempo de utilização do mesmo. 
Dessa forma, a disposição final dos resíduos sólidos em aterros pode assumir duas formas principais: aterro controlado e aterro sanitário. Nos aterros controlados os resíduos são compactados e formatados por um trator para melhor ordenamento. O lixo adensado é coberto por materiais de jazida (barro próprio para recobrimento) evitando dispersão de odores, presença de vetores de doenças (moscas, mosquitos, baratas, ratos, etc.), animais nocivos e combustão espontânea por anaerobiose, minimizando os riscos de impactos ambientais e à saúde pública (Falcão \& Araujo, 2005 apud Soares, Salgueiro \& Gazineu , 2007)

Já o aterro sanitário é uma forma de disposição final baseada em critérios de engenharia e normas operacionais específicas (Soares, Salgueiro \& Gazineu, 2007). O local é normalmente recoberto por material de jazida, selecionado e compactado em níveis satisfatórios. Os aterros sanitários possuem um sistema de drenagem periférica e superficial para captação de águas pluviais e um sistema de drenagem específica para captação e condução ao local de tratamento de líquidos percolados. Segundo Soares, Salgueiro e Gazineu (2007), esse tratamento pode ser através de lagoas de estabilização que operam num sistema físico químico de recuperação dos líquidos, objeto do processamento. Existe também um sistema de captação para os gases, principalmente o gás carbônico, o gás metano e o gás sulfídrico para que o terreno não fique sujeito a explosões, deslizamentos e combustão.

\subsection{Gestão pública de resíduos sólidos}

A excessiva geração de resíduos sólidos constitui um desafio de ordem global. No entanto, é no âmbito municipal que seus impactos são vivenciados. De acordo com Lopes (2003) um dos principais problemas enfrentados por uma administração, seja pública ou privada, diz respeito aos resíduos sólidos, o qual é produzido por diversas atividades humanas, gerando graves problemas sociais, políticos, econômicos, técnicos, ambientais e de saúde.

Besen (2006) destaca que as administrações municipais enfrentam diariamente o desafio de promover a limpeza pública, fiscalizar, coletar, tratar e dispor os resíduos sólidos domiciliares que são de sua exclusiva responsabilidade. Contudo, além dos problemas socioambientais gerados pela disposição inadequada dos resíduos, tais como a ocorrência de lixões e as enchentes, existem dificuldade gerenciais na coleta, tratamento e disposição final, como também impactos do alto custo de seu gerenciamento nos orçamentos das cidades.

Goes (2011) relata que, apesar da competência municipal quanto ao serviço público de limpeza urbana e manejo de resíduos sólidos, os incisos VI e IX do art. 23 da CF/1988 estabelecem como atribuição comum da União, dos Estados, do Distrito Federal e dos municípios protegerem o meio ambiente e combater a poluição em qualquer das suas formas, bem como promover programas de construção de moradias e a melhoria do saneamento básico.

No entanto, Paes (2004) explana que mesmo sendo de responsabilidade do município, o gerenciamento do sistema de limpeza urbana, objetivando afastar o lixo das populações e dando um destino final ecologicamente adequado, esta tarefa não é fácil. De acordo com Jardim et al. (1995), o correto gerenciamento dos resíduos sólidos apresenta uma série de problemas, principalmente, pelos seguintes motivos:

i. Inexistência de uma política brasileira de limpeza pública;

ii. Limitação financeira - orçamentos inadequados, fluxo de caixa

iii. Desequilibrado, tarifas desatualizadas, arrecadação insuficiente e

iv. Inexistência de linhas de crédito;

v. Descontinuidade política e administrativa; 
vi. Falta de controle ambiental.

Para combater esta problemática, a gestão do serviço de limpeza deverá tomar uma série de decisões estratégicas, usando ferramentas apropriadas de manejo gerencial (Carvalho, 2001). Nessa perspectiva, segundo Jardim et al. (1995), as prioridades máximas, para qualquer modelo de gerenciamento para os resíduos devem ser coletar todo o lixo gerado de responsabilidade da prefeitura; dar um destino final adequado para o lixo; buscar formas de tratamento para o lixo de seu município (considerar que estas formas só darão resultados positivos e duradouros se responderem a claros objetivos tanto ambientais como econômicos); e fazer campanhas ou implantar programas educacionais voltados à conscientização pela limpeza da cidade e incentivar medidas que visem diminuir a própria geração do lixo.

\section{Procedimentos metodológicos}

Esta pesquisa iniciou-se através de levantamento. Para Vergara (2009) a pesquisa bibliográfica refere-se ao tipo de estudo organizado, desenvolvido a partir de materiais acessíveis ao público, tais como: livros, revistas, jornais, pesquisas, artigos, entre outros. Lakatos (2010) complementa que até os meios de comunicação oral, como rádio e gravações em fita magnética e audiovisuais como filmes e televisão, também são fontes para este tipo de trabalho, de modo que não se trata apenas de repetir o que já foi dito ou escrito sobre determinado assunto, mas sim, propiciar o exame de um tema sob novo enfoque ou abordagem, chegando a novas conclusões.

O estudo também se deu por meio de pesquisa de campo, pois, se faz necessário observar o cenário e conhecer a percepção da população em relação aos resíduos sólidos e o gerenciamento no município de Belém de Maria. Pesquisa de campo é a investigação empírica realizada no local onde ocorre ou ocorreu um fenômeno ou que dispõe de elementos para explicá-lo (Vergara,2009).

Por fim, vale mencionar que a pesquisa também foi desenvolvida através de estudo de caso. Segundo Yin (2001), o estudo de caso pode ser definido como uma pesquisa empírica que examina um fenômeno contemporâneo dentro de sua realidade. Assim, para esta pesquisa foi realizado um estudo de caso com a população do município de Belém de Maria para atender aos objetivos propostos pelo artigo.

Para conhecer como é realizado o gerenciamento dos resíduos sólidos urbanos no município de Belém de Maria optou-se por uma abordagem de cunho qualitativo. Lima (2001), citado por Rodrigues (2011), diz que por pesquisa qualitativa entende-se o enfoque investigativo, cuja preocupação principal é compreender os fatos, descrever o objeto de estudo, interpretar seus valores e relações, não dissociando o pensamento da realidade dos atores sociais, onde pesquisador e pesquisado são sujeitos comuns, e por consequência, ativos no desenvolvimento da investigação científica.

No que diz respeito a coleta de dados da prefeitura municipal, mas especificamente do setor de infraestrutura, entrevistou-se o secretario deste órgão. Utilizou-se entrevista não estruturada, seguindo um roteiro de pesquisa. Já como instrumento de coleta de dados da população de Belém de Maria, aplicou-se 100 questionários, composto por perguntas de abordagens relacionadas aos resíduos sólidos e ao gerenciamento no munícipio, com questões objetivas e discursivas. O período de aplicação dos questionários foi de outubro a novembro de 2018. Para delimitação do número de questionários utilizou-se o critério de "exaustão" "saturação", em que o pesquisador aplica os questionários em números suficientes para permitir a reincidência das informações, garantindo um máximo de diversificação para reconstituição do objeto no conjunto do material, verificando assim a formação de um todo (Minayo,1999). 
Após a coleta de dados e informações, eles foram analisados de forma descritiva. Segundo Vergara (2009), esse tipo de análise de dados expõe características de determinada população ou determinado fenômeno.

\section{Resultados e discussão}

No intuito de analisar o gerenciamento de resíduos sólidos urbanos no município de Belém de Maria, foram constatados através de entrevistas realizadas com o secretário de infraestrutura do município os procedimentos realizados pela gestão pública. Existe um roteiro a ser seguido para a gestão dos resíduos, que consiste basicamente na varredura de todos os logradouros e coleta dos resíduos, onde cada gari é responsável por um determinado local e uma determinada tarefa. Essa constatação corrobora com os achados na entrevista realizada com a população: $96 \%$ apontaram que são atendidas pela coleta de resíduos sólidos urbanos, em contraposição aos $4 \%$ restantes.

Em entrevistas realizadas com o secretário de infraestrutura, tomou-se conhecimento de que os garis envolvidos na atividade de coleta recolhem os resíduos domiciliares deixados nas ruas de segunda a sábado, duas vezes ao dia, em horários determinados, em pequenos carrinhos de estrutura metálica montada sobre rodas de borracha, ou nas chamadas "caçamba de lixo". Esta realidade condiz exatamente com as respostas obtidas através de aplicação de questionários à população, visto que a maioria, $87 \%$ das pessoas responderam que a frequência da coleta pública de resíduos sólidos urbanos acontece 5 ou mais vezes por semana.

Vale salientar também que a prefeitura disponibiliza pequenas cestas metálicas coletoras de resíduos em alguns pontos da cidade, as quais poderiam ser substituídas por cestas de coleta seletiva, no intuito de despertar na população o sentindo ambiental, econômico e social de reaproveitar e reciclar materiais. Sugere-se ainda a implantação da coleta seleta no município, a fim de que os materiais que podem ser reaproveitados não sejam misturados com aqueles que seguem para o lixão. Se faz necessário ainda, que a gestão do município realize incentivos a alguma cooperativa ou entidade onde se possa fazer a reciclagem do material.

Em relação a presença de lixeiras encontradas nas ruas, apenas $14 \%$ dos entrevistados declararam que em suas ruas há lixeiras públicas, e as demais $86 \%$, que não existe. Apesar desta ou constatação, e embora não haja lixeiras em quantidade razoável nas ruas da cidade, cada indivíduo deve ser responsável pela produção e disposição final do lixo.

Da população respondente, quando questionada qual a maior dificuldade encontrada com os resíduos sólidos em suas ruas, $59 \%$ indicaram que os resíduos jogados no chão se constituem como o maior problema. Constatou-se ainda que a maior parcela desses resíduos é de entulhos de construção. $1 \%$ declarou que é o aparecimento de animais peçonhentos pelo acúmulo de lixo e as demais $40 \%$ que não há problemas.

A destinação final adequada dos resíduos sólidos ainda continua sendo um dos maiores problemas enfrentados pela administração pública, pois boa parte dos municípios do país despeja seus resíduos em lixões a céu aberto com ausência de tratamento. Assim, a fim de diagnosticar a percepção da população em relação a disposição que é dada aos resíduos sólidos produzidos pelos seus domicílios, e consequentemente pelo município, 69\% dos entrevistados indicaram que os resíduos seguem para lixão, enquanto $24 \%$ não sabem e $3 \%$ e $4 \%$ apontaram para lançamento a céu aberto e terreno baldio, respectivamente.

No entanto, o que poucas pessoas sabem, é que antes de seguir para o lixão, o lixo do município é despejado em dois pontos na cidade (terrenos baldios), o que pode causar degradação do solo, comprometimento dos corpos d'água e mananciais, intensificação de enchentes, contribuição para a poluição do ar e proliferação de vetores de importância sanitária (Besen et al., 2010). Segundo a gestão pública do município, todos os dias a caçamba faz a coleta nos terrenos 
baldios, onde o lixo fica lançado a céu aberto, e segue para o município de Agrestina, cidade que fica a aproximadamente $87 \mathrm{~km}$. Consequentemente, Belém de Maria se enquadra no percentual de mais de 70\% dos municípios que utilizam formas inadequadas de disposição final (IBGE,2010).

Assim, como os municípios de pequeno e médio porte brasileiros têm dificuldade para tratar os resíduos sólidos, por não disporem de recursos suficientes e terem pouca capacidade técnicas na gestão dos serviços de limpeza pública, coleta seletiva e tratamento de resíduos, a formação de consócios públicos municipais pode proporcionar a sustentabilidade dos serviços prestados e a divisão das despesas, além de contribuir para a inclusão social de catadores e a desativação de lixões (Brasil, 2011, p. 6). No que tange aos pontos de concentração de lixo no munícipio, um fica na parte alta da cidade, próximo ao Cemitério São Francisco, e o outro na parte baixa, num local conhecido como "Intendência".

Com o objetivo de examinar o conhecimento das pessoas em relação ao termo resíduo sólidos, apenas 8\%indicaram saber do que se trata. Já em relação a palavra lixo, $97 \%$ responderam que lixo é tudo aquilo que não tem serventia, não presta, não têm utilidade, que é podre e jogado fora de casa. Como exemplo, citaram garrafa, restos de comida, objetos contaminados, papel, embalagens, entre outros. Apenas 3\% das pessoas não responderam a esta questão. Assim, entendese que a população tem pouco conhecimento a respeito dos resíduos por ser considerado 'lixo', e tal fator pode estar atribuído a falta de informações, e de políticas públicas.

Já em relação ao tipo de resíduo mais produzido nas residências, $62 \%$ dos entrevistados apontaram para restos de alimentos (matéria orgânica), $26 \%$ plásticos, o qual é constituído por embalagens de produtos, garrafas PET, entre outros, $8 \%$ papel e o restante vidro e metais. Diante desses achados, a composição de resíduos sólidos de Belém de Maria está inserida no perfil nacional, cuja estimativa da composição é: 57,41\% de matéria orgânica (sobras de alimentos, alimentos deteriorados, lixo de banheiro), $16,49 \%$ de plástico, $13,16 \%$ de papel e papelão, 2,34\% de vidro, $1,56 \%$ de material ferroso, $0,51 \%$ de alumínio, $0,46 \%$ de inertes e $8,1 \%$ de outros materiais (Besen, 2011).

Assim, pode se aplicar o tratamento da compostagem para os resíduos orgânicos e reciclagem para aqueles que podem ser reaproveitados, já que, de acordo com D'Almeida (2000), a compostagem é um processo biológico de decomposição da matéria orgânica contida em restos de origem animal ou vegetal tendo como resultado final um produto que é o composto orgânico. $\mathrm{O}$ composto gerado pode ser aplicado ao solo para melhorar suas características sem ocasionar risco ao meio ambiente (D’Almeida, 2000 apud Junkes, 2012). Além da compostagem, o processo de reciclagem pode ser estimulado, com a coleta, separação e processamento dos resíduos para serem reutilizados (Jardim, 1995).

Considerando que a população tem um forte papel no que diz respeito ao adequado gerenciamento dos resíduos sólidos domiciliares, foi perguntado aos entrevistados a maneira pela qual é realizada o acondicionamento do lixo. A maioria (92\%) diz ter o hábito de usar sacolas plásticas, enquanto $3 \%$ utiliza lixeira metálica, $4 \%$ lixeira de borracha e 1\% outros. No entanto, foi observado que ao colocar as sacolas plásticas de lixo na rua, elas acabam sendo rompidas pelos animais que espalham todo lixo.

Questionados quanto ao hábito de fazer a separação do lixo em casa, 83\% dos entrevistados responderam que não o fazem, justificando a falta costume, tempo e que não adiantaria. Isso porque em Belém de Maria não possui serviço de coleta seletiva e todos os resíduos vão para o mesmo local. Os 17\% responderam que fazem sim a separação do lixo. Quanto a achar que o lixo poderia ser aproveitado de alguma forma $78 \%$ responderam que sim, em contraposição a $22 \%$.

No que tange aos conhecimentos dos problemas que os resíduos sólidos podem causar se depositados de modo inadequado, $76 \%$ têm conhecimento e apontaram entupimentos de bueiros, enchentes, poluição dos rios, como problemas que podem ser causados pela má disposição final dos resíduos sólidos. Apenas $24 \%$ apontaram não ter conhecimentos sobre essa questão. 
Mesmo acreditando que o lixo pode ser aproveitado de alguma forma e usufruindo consciência quantos aos problemas que os resíduos sólidos depositados inadequadamente podem trazer, a população mostrou-se com hábitos irregulares quanto a proteção com o meio ambiente e os descartes de alguns resíduos como pilhas/baterias e óleos de cozinhas. Esta realidade sugere a gestão municipal um incentivo na educação ambiental junto às comunidades e no ambiente escolar, formando a consciência ambiental na população, com o intuito de promover a adoção de comportamentos ambientalmente adequados.

O que Fritsch (2000) diz é que produzir resíduos é inerente ao ser humano e que destiná-los adequada e satisfatoriamente é o maior desafio das administrações públicas. Essa atividade não pode ser exercida sem a colaboração direta do munícipe. Assim, se faz necessário que governo municipal e cidadãos colaborem para um correto gerenciamento dos resíduos sólidos no município de Belém de Maria.

\section{Conclusão}

A partir das análises realizadas foi possível identificar alguns desafios que merecem atenção dos gestores públicos, bem como da população, pois o gerenciamento dos resíduos sólidos apresenta irregularidades desde a geração até a destinação e disposição final dos resíduos.

Constatou-se que os funcionários responsáveis pela limpeza são orientados recolher o lixo o lixo urbano e os colocam em uma área mais afastada do cenário urbano, sem nenhum tratamento, o que pode causar danos à saúde ambiental e populacional. Após ser despejado nestas áreas mais afastadas, os resíduos são coletados pela caçamba de lixo e segue para a disposição final, todos os dias, que é o lixão a céu aberto no município de Agrestina. Porém a Lei no 12.305/2010 determina que todos os lixões do Brasil sejam erradicados. Para isso, sugere- se a criação de consócios públicos municipais, a fim de proporcionar a sustentabilidade dos serviços prestados e a divisão das despesas, além de contribuir para a inclusão social de catadores e a desativação dos lixões.

Os achados também evidenciaram a existência de cestas coletoras de lixo em alguns pontos da cidade, as quais poderiam ser substituídas por conjuntos de lixeiras de coleta seletiva para despertar na população o sentindo ambiental, econômico e social de reaproveitar e reciclar materiais. Sugere-se a implantação da coleta seleta no município, para que os materiais que podem ser reaproveitados não sejam misturados com aqueles que seguem para o lixão. Isso demanda da gestão pública do município investimentos e parcerias com cooperativa ou entidade que possa fazer a reciclagem do material.

Quanto ao tipo de resíduo mais produzidos pelos domicílios de Belém de Maria, a maioria apontou para restos de alimentos (material orgânico). Com isso, sugere-se a compostagem como forma de tratamento. Se coletado de forma seletiva, os resíduos orgânicos podem ser utilizados para a produção de adubos, por exemplo, o que pode gerar renda.

A maioria do público entrevistado mostrou-se consciente dos problemas que os resíduos sólidos podem causar, porém, mesmo com este discernimento, a população entrevistada é responsável por práticas insustentáveis. Diante desse cenário apresentado, sugere-se a gestão municipal um incentivo na educação ambiental junto às comunidades e no ambiente escolar.

Assim, tendo em vista os resultados apresentados, pode-se concluir que o objetivo da pesquisa foi atingido de maneira satisfatória, pois foi identificado e descrito o cenário da gestão dos resíduos sólidos urbanos no município de Belém de Maria, bem como é realizado o seu gerenciamento, o que proporcionou a possibilidade de propor melhorias capazes de potencializar a efetividade da gestão dos resíduos sólidos urbanos no município.

Entre as sugestões, cita-se a participação do município na formação de consórcios públicos para a destinação final correta dos resíduos sólidos; a eliminação de lixões a céu aberto; a 
implantação de coleta seletiva; a realização de incentivos a cooperativas e entidades onde se possa reciclar materiais; a substituição de cestas metálicas por cestas de coleta seletiva, bem como o aumento na distribuição dessas cestas nas ruas; a compostagem como forma de tratamento dos resíduos orgânicos, os mais produzidos na cidade, e a reciclagem para os demais que podem ser reaproveitados; e programas de educação ambiental para toda a população com o intuito de sensibilizar quanto às questões sobre resíduos sólidos urbanos.

Em relação as principais limitações deste estudo expõem-se a dificuldade de encontrar disponibilidade por parte da população para responder aos questionários. Recomenda-se a investigação desta temática em outros municípios, com o intuito de se buscar resultados mais aprofundados em relação ao correto gerenciamento dos resíduos sólidos.

\section{Referências}

ABNT. (2004). Resíduos sólidos - Classificação. Rio de Janeiro.

ABRELPE. (2015). Panorama 2015.

ABRELPE. (2017). Panorama 2017.

Andrade, A. O.; et al. (2018). A questão ambiental e a sustentabilidade. Manaus.

Amorim , A.P. et al. (2010). Lixão municipal: abordagem de uma problemática ambiental na cidade de Rio Grande - RS. Revista de Educação Ambiental, v. 15, n. 1, p. 159-177.

Bellen, H. M. van. (2005) Indicadores de Sustentabilidade: Uma Análise Comparativa. Rio de Janeiro: Editora FGV.

Besen, G. R. (2009) Programas municipais de coleta seletiva em parceria com organizações de catadores na região metropolitana de São Paulo: desafios e perspectivas. São Paulo.

Besen, G. R. (2011) Coleta seletiva com inclusão de catadores: construção participativa de indicadores e índices de sustentabilidade. São Paulo.

Besen, G. R., \& Ribeiro, H. (2007) Panorama da coleta seletiva no Brasil: desafios e perspectivas a partir de três estudos de caso. São Paulo: Revista de Gestão Integrada em Saúde do Trabalho e Meio Ambiente.

Brasil. (APA) (2007) Lei $n^{\circ} 11.445$, de 5 de janeiro de 2007. Estabelece diretrizes nacionais para o saneamento básico; altera as Leis nos 6.766, de 19 de dezembro de 1979, 8.036, de 11 de maio de 1990, 8.666, de 21 de junho de 1993, 8.987, de 13 de fevereiro de 1995; revoga a Lei $n^{o}$ 6.528, de 11 de maio de 1978; e dá outras providências.

Brasil. (APA) (2010) Lei $n^{o}$ 12.305, de 2 de agosto de 2010. Institui a Política Nacional de Resíduos Sólidos; altera a Lei no 9.605, de 12 de fevereiro de 1998; e dá outras providências.

Borges, N. R. M., Castilho, A. P., \& Pereira, V. T. (2011) Manual de metodologia científica do ILES Itumbiara/GO. Itumbiara: ILES/ULBRA.

Carvalho, L.E.X. (2001) Desenvolvimento de solução integrada de sistemas de limpeza urbana em ambiente SIG. Dissertação (Mestrado em Ciências em Engenharia de Transportes), Rio de Janeiro-RJ, Universidade Federal do Rio de Janeiro - UFRJ, 240 p.

Castilho Junior, A. B. (coord.). (2003) Resíduos sólidos urbanos: aterro sustentável para municípios de pequeno porte. 1. ed. Rio de Janeiro: ABES, 2003.

Costa, B. S., \& Ribeiro, J. C. J. Gestão e gerenciamento de resíduos sólidos: direitos e deveres. Rio de Janeiro: Lumen Juris, 2013. 
Cruz, R. G, \& Bigliardi, R. V. (2005) A Teoria da Complexidade como base para o Enfrentamento da Crise Ambiental e da Racionalidade Teórico Instrumental. Revista Eletrônica do Mestrado em Educação Ambiental. v- 15, p. 12.

Darós, T. D.; et al. A Percepção Ambiental Como Instrumento de Apoio na

Gestão e na Formulação de Políticas Públicas Ambientais. São Paulo: Saúde e Sociedade,

2012. Disponível em: <http://www.scielo.br/pdf/sausoc/v21s3/09.pdf>. Acesso em: 22 set.2018.

Dyniewicz, A. M. (2006) Curso de avaliação efetividade de promoção a saúde. Curitiba.

França, R. G., \& Ruaru, E. C. R. (2009) Diagnóstico da disposição final dos resíduos sólidos urbanos na região da Associação dos Municípios do Alto Irani (AMAI), Santa Catarina. Rio de Janeiro: Ciência saúde coletiva.

Fritsch, I. E., (2000). Resíduos Sólidos e seus aspectos legais, doutrinários e jurisprudenciais. Porto Alegre, EU/Secretaria Municipal da Cultura, p. 143.

Galeno, J. J. A. (2017) Gestão de resíduos sólidos: Análise dado pelos meios de hospedagem do centro histórico de São Luis. São Luis.

Godoy, A. S. (1995) Introdução à pesquisa qualitativa e suas possibilidades. São Paulo: Revista de Administração de Empresas.

Gurski, B., Gonzaga, R., \& Tendolni, P. Conferência de Estocolmo: Um marco na questão ambiental. Curitiba.

IBGE. IBGE Cidades: Panorama de Belém de Maria.

IPEA. (2010) Brasil perde $R \$ 8$ bilhões anualmente por não reciclar. Brasília.

IPEA. (2013) Situação social das catadoras e dos catadores de material reciclável e reutilizávelBrasil. Brasília.

Jacobi, P. R.; Besen, G. R. (2011) Gestão de resíduos sólidos em São Paulo: desafios da sustentabilidade. São Paulo.

Jardim, N.S.; WELLS, C.; Prandini, F.L.; D’Almeida, M.L.O.; Mano, V.G.T. (cords.) (1995) Lixo Municipal: Manual de Gerenciamento integrado. São Paulo: IPT/CEMPRE.

Junior, A. P., Roméro, M. A., Bruna, G. C. (2004) Curso de Gestão Ambiental. Barueri, SP: Manole.

Junkes, M. B. (2002) Procedimentos para aproveitamento de resíduos sólidos urbanos em municípios de pequeno porte. Florianópolis.

Klein, F. B., Gonçalves-Dias, S. L. F.; Jayo, M. (2018) Gestão de resíduos sólidos urbanos nos municípios da Bacia Hidrográfica do Alto Tietê: uma análise sobre o uso de TIC no acesso à informação governamental. Curitiba: Revista Brasileira de Gestão Urbana.

Lakatos, E. M. Fundamentos de metodologia científica. São Paulo: Atlas, 7ed.

Leme, S. M. (2009) Comportamento da população urbana no manejo dos resíduos sólidos domiciliares em Aquidauana - MS. Londrina.

Lima, A. M. et al. (2013) Gestão de resíduos urbanos: um estudo da percepção dos munícipes acerca da implantação da coleta seletiva em Aripuanã - MT. Rio de Janeiro: IX Congresso Nacional De Excelência Em Gestão.

Lira, E. M. (2012) Análise da concepção dos resíduos sólidos entre moradores e agentes de saúde no bairro no Alto do Mandu - Recife, Pernambuco, Brasil. Recife: 2012. 
Medeiros, J. H. D. (2012) Gestão dos Resíduos Sólidos para Municípios de Pequeno e Médio Porte à Luz da Política Nacional de Resíduos Sólidos. Angicos.

Melo, E. S. (2017) A Trajetória Social dos Catadores de Lixo em Santana/AP - Brasil. Lisboa.

Mucelin, C. A., \& Bellini, M. (2008) Lixo e impactos ambientais perceptíveis no ecossistema urbano. Uberlândia: Sociedade \& Natureza.

Pacheco, J. R. (2004) Estudo de certas potencialidades de processos oxidativos avançado para o tratamento de percolado de aterro sanitário. Curitiba.

Paes, F. G. (2004) Otimização de rotas para a coleta do lixo doméstico: um tratamento GRASP do Problema Do Carteiro Chinês Misto (PCCM). Campos do Goytacazes.

Portela, M. O., \& Ribeiro, J. C. J. (2014) Aterros sanitários: aspectos gerais e destino final dos resíduos. Caxias do Sul: Direito Ambiental e sociedade.

Oliveira, T.B. \& Galvão Junior, A.C. (2016) Planejamento municipal na gestão dos resíduos sólidos urbanos e na organização da coleta seletiva. EngSanitAmbient, v.21, n.1. pp. 55-64

Ribeiro, T. F., \& Lima, S. C. (2000) Coleta seletiva de lixo domiciliar - estudo de casos. Uberlândia: Caminhos da Geografia.

Rovaris, N. R. S., \& Santos, T. (2017) Cenário brasileiro da gestão dos resíduos sólidos urbanos e coleta seletiva. São Paulo: Anais do VI SINGEP.

Rodrigues, B. P., Brito, F. M. S., \& Campanharo, W. A.. (2011) Pesquisa Qualitativa versus quantitativa. Jerônimo Monteiro.

Silva, A. C.; et al. (2016) Política nacional de resíduos sólidos (Lei 12.305/2010) e sua aplicabilidade no município de Bacabal - MA. Campina Grande: VII Congresso Brasileiro de Gestão Ambiental.

Soares, L. G. C., Salgueiro, A. A., \& Gazineu, M. H. P. (2007) Educação ambiental aplicada aos resíduos sólidos na cidade de Olinda, Pernambuco - um estudo de caso. Recife: Ciência e Tecnologia.

Valença, K. F. P, \& Oliveira, T. A. B. (2006) A importância da metodologia científica para o ensino e aprendizagem no ensino superior.

Vergara, S. C. (2009) Projetos e relatórios de pesquisa em administração. São Paulo: Atlas, 10 ed.

Vieira, E. A. (2006) Lixo - problemática sócio espacial e gerenciamento integrado: a experiência de Serra Azul (SP). Rio Claro.

Yin, R. K. (2001) Estudo de caso: planejamento e métodos. 2 ed. Porto Alegre: Bookman.

\title{
Analysis of solid waste management in Belém de Maria City (Pernambuco)
}

\begin{abstract}
This article aims to analyze solid waste management in Belém de Maria - Pernambuco. The research was conducted through case study, bibliographic and field research. Interviews and questionnaires were conducted to the public management and the population, aiming to obtain data on their positioning regarding the management and the problem of solid waste in the city. The results show that there are collection services, however, the correct ways of disposal of solid waste
\end{abstract}


are not being met, since the waste is collected and dumped at distant points of the urban scenario to then go to the final destination: the dump. However, it is noteworthy that the population is aware of the existing scenario, as well as identifies the problems caused by garbage, however, have reprehensible attitudes of environmental education. Thus, this research also allowed us to understand the need for changes in solid waste management, such as: implementation of selective collection, participation in the formation of public consortia, solid waste treatment through recycling and composting, and environmental education actions that contribute to arouse the need for political and public collaboration.

Keywords: Urban solid waste, Trash, Environmental perception, Management, Belém de Maria Pernambuco.

\section{Sobre os Autores}

\section{Jaisy GONÇALVES}

Graduada em Administração pela Universidade Federal de Pernambuco (UFPE), Centro Acadêmico do Agreste (CAA).

Avenida Campina Grande, s/n, km 59, Nova Caruaru, Caruaru, PE, Brasil, CEP 55014-900.

E-mail: jaisy-gfl@hotmail.com

\section{Luciana CRAMER}

Doutora em Administração pela Universidade Federal de Lavras, Professora da Universidade Federal de Pernambuco (UFPE), Centro Acadêmico do Agreste (CAA).

Avenida Prof. Moraes Rego, 1235, Cidade Universitária, Recife, PE, Brasil, CEP 50670-8000.

E-mail: lucianacramer@terra.com.br

\section{Ítalo Cavalcante da Silva SOARES}

Mestre em Gestão e Desenvolvimento Local Sustentável (GDLS/UPE) e Técnico Administrativo da Universidade Federal de Pernambuco (UFPE/CAA).

Avenida Campina Grande, s/n, km 59, Nova Caruaru, Caruaru, PE, Brasil, CEP 55014-900.

E-mail: italo_cs_1@hotmail.com 